\title{
LENGUAS MINORITARIAS DE VENEZUELA: CONSIDERACIONES DESDE LA PERSPECTIVA ECOLINGÜÍSTICA
}

\author{
Natalia Bondarenko
}

\begin{abstract}
RESUMEN
El artículo trata la problemática de la sobrevivencia de las lenguas minoritarias (lenguas indígenas y lenguas de las diásporas extranjeras) en Venezuela. Los objetivos fueron explicar el origen, la evolución y el mantenimiento de la diversidad lingüística del país, desde la perspectiva ecolingüística, y hacer las proyecciones para el futuro. Luego de explicar el concepto de la ecología lingüística y comparar sus objetos de estudio con los de la lingüística, se procede a definir el contacto lingüístico como punto de partida donde comienza la merma en el número de hablantes de la lengua minoritaria, presentar la distribución funcional de usos como factor principal para estimar la continuidad de la lengua minoritaria y proponer las medidas de una oportuna intervención ecolingüística para rescatar una lengua amenazada, siempre tomando en cuenta la voluntad del grupo lingüístico respectivo. Se concluye que el modelo de la sostenibilidad ecolingüística se impone como una oportunidad para el mantenimiento de la diversidad lingüística venezolana, por el camino de la justicia y la equidad sociolingüística.
\end{abstract}

Palabras clave: lengua minoritaria, contacto lingüístico, distribución funcional, intervención ecolingüística, sostenibilidad ecolingüística.

\begin{abstract}
The article deals with the problem of survival of minority languages (indigenous languages and languages of foreign diasporas) in Venezuela. The objectives were to explain the origin, evolution and maintenance of the linguistic diversity of the country, from the ecolinguistics perspective, and to make projections towards the future. After explaining the concept of linguistic ecology and comparing its objects of study to those of linguistics, the article proceeds to define linguistic contact as a starting point where begins the decline in the number of speakers of the minority language, to present the functional distribution of uses as the principal factor to estimate the continuity of the minority language, and to suggest measures for a prompt ecolinguistic intervention in order to rescue the endangered language, always taking into account the will of the respective linguistic group. It is concluded that ecolinguistic sustainability model presents itself as an opportunity for the maintenance of the linguistic diversity of Venezuela, along the road of sociolinguistic justice and equality.
\end{abstract}

Key words: minority language, linguistic contact, functional distribution, ecolinguistic intervention, ecolinuistic sustainability.

Dra. Natalia Bondarenko. Profesora Agregada, Investigador-Docente. Universidad de Oriente, Isla de Margarita, Venezuela.

Correo electrónico: npisemskaya@gmail.com

Recepción: 17- 05- 2010

Aceptación: 20- 09- 2010 


\section{Introducción}

El tema de las lenguas minoritarias de Venezuela tiene mucho que ver con la identidad nacional y con la venezolanidad. En su discurso de Angostura, Simón Bolívar señalaba que “[...] los americanos no éramos ni europeos, ni africanos, ni aborígenes" (Bolívar 1819/1975). En efecto, Venezuela es uno de los países del mundo con mayor diversidad cultural: a partir del período colonial, en nuestro país se mezclaron indígenas, españoles y africanos, y actualmente la mayoría de los venezolanos tiene una o más de estas ascendencias: $67 \%$ mestizos, $21 \%$ europeos, $10 \%$ negros, $1 \%$ indígenas, con un $1 \%$ de otros (XIII Censo General de Población y Vivienda 2001). Por otro lado y desde el punto de vista lingüístico, Venezuela es un país multilingüe o lingüísticamente heterogéneo, donde en el mismo territorio cohabitan diversas lenguas, entre ellas el español (o el castellano), lengua materna del 90\% de la población (Serrón 2007a), las lenguas indígenas y las lenguas de las diásporas extranjeras que hacen vida en el territorio nacional. Por estas razones, la situación cultural-lingüística de Venezuela se puede caracterizar como intrínsecamente compleja.

Las lenguas más antiguas de Venezuela son las lenguas indígenas, las cuales, históricamente, habían tenido miles de años de existencia antes de la llegada de los colonizadores españoles. De acuerdo con Mosonyi (2007), para el año 1500, en Venezuela convivían cerca de cien idiomas indígenas. Durante miles de años, los padres indígenas enseñaban y transmitían su propio idioma a los nuevos miembros de la familia. En nuestros tiempos, de las cien lenguas originarias solamente un poco más de treinta permanecen vivas, pero la situación de la gran mayoría de ellas es delicada: como resultado de los intercambios crecientes con la cultura criolla, los miembros más jóvenes de estas culturas o bien se vuelven bilingües, o usan únicamente el español. Algunas de estas lenguas, como, por ejemplo, el warekena, el arutani, el mako o el sapé, están a punto de desaparecer, y tanto hablantes como investigadores se plantean la interrogante acerca de las posibilidades de sobrevivencia de estas lenguas.

Inmediatamente después del inicio de la conquista y la colonización, se agrega al panorama lingüístico venezolano el elemento extranjero. Desde siempre, Venezuela ha estado abierta a numerosos flujos migratorios desde diversas partes del mundo, pero en el siglo XX el "boom" petrolero de los años setenta hizo que Venezuela se volviera nuevamente atractiva para los inmigrantes de diferentes países y portadores de diversas lenguas. Entre los hablantes de otras lenguas que no sean el español, los más numerosos son los italianos, los portugueses, los chinos, los árabes y los descendientes de los colonos alemanes (el Censo General de Población y Vivienda de 2001 los registra como las principales colonias extranjeras establecidas en el país); sin embargo, a diferencia de las olas migratorias anteriores al siglo XX, su integración cultural y lingüística a la sociedad venezolana no ha sido uniforme, debido principalmente a que las grandes cantidades de personas del mismo origen que ingresaban al país se mantenían unidas como comunidad y no se mezclaban tan fácilmente con la población criolla. Al igual que en el caso de las lenguas indígenas, con respecto a este tema, surge la interrogante acerca de cómo mantienen los inmigrantes su herencia lingüístico-cultural y cuáles son las perspectivas de la permanencia futura de estas lenguas en el territorio venezolano.

El siguiente cuadro recoge las principales lenguas minoritarias de Venezuela y su número aproximado de hablantes, conforme con los datos del XIII Censo General de Población y Vivienda (2001). 
Cuadro 1. Lenguas minoritarias de Venezuela

\begin{tabular}{|l|l|l|}
\hline $\mathbf{N}^{\circ}$ & Lengua de la comunidad lingüística minoritaria & Número aproximado de hablantes \\
\hline 1. & Lenguas Indígenas (36) & 400.000 \\
\hline 2. & Lengua italiana & 600.000 \\
\hline 3. & Lengua portuguesa & 500.000 \\
\hline 4. & Lengua árabe & 400.000 \\
\hline 5. & Lengua china & 160.000 \\
\hline 6. & Alemán Coloniero & 10.000 \\
\hline 7. & Lenguas de otras diásporas extranjeras & 340.000 \\
\hline \multicolumn{2}{|c|}{ TOTAL } & 2.410 .000 \\
\hline
\end{tabular}

Para contestar de alguna manera a las interrogantes expresadas anteriormente, el enfoque de ecolingüística, teorizado en los trabajos de Haugen (1972), Calvet (1999) y Bastardas-Boada (2007), entre otros, plantea la posibilidad de conservar la diversidad lingüística de un país como Venezuela, conciliando las tendencias opuestas de expansión de la lengua dominante y preservación y consolidación de las lenguas minoritarias. A continuación, se profundizará en los orígenes de la diversidad linguiística venezolana, en la problemática de la conservación de algunas lenguas minoritarias y la extinción paulatina de otras, en las intervenciones ecolingüísticas preventivas y en las posibilidades de la conservación de la diversidad lingüística de Venezuela en el tiempo.

\section{El enfoque ecolingüístico: un encuentro entre la ecología y la lingüística}

En términos generales, la ecolingüística puede definirse como estudio de las interacciones dinámicas entre la lengua y la sociedad que la usa como uno de sus códigos comunicacionales. El concepto de la ecolingüística fue utilizado por primera vez por Haugen (1972), cuando éste se refería a las interacciones entre la lengua y su entorno, tanto psicológico como sociológico. El entorno psicológico implica que la lengua existe únicamente en las mentes de sus hablantes y sólo funciona relacionándolos los unos con los otros; en las mentes de los hablantes bilingües y multilingües, esta lengua también se relaciona con otras lenguas. A su vez, el entorno sociológico consiste en la interacción de la lengua con la sociedad en la cual ésta funciona como medio de comunicación y con otras lenguas que se hablan en la misma. De esta manera, la ecología de una lengua es condicionada principalmente por las personas que la aprenden, la usan y la transmiten a otros. Desde esta perspectiva, las lenguas se imponen como aspectos del comportamiento humano y en este sentido, adquieren vida, propósito y forma; cada uno de estos aspectos es objeto de estudio de la ecolinguíística. Pero esta ciencia no se limita únicamente a la descripción y al estudio teórico de la situación de cada lengua, sino que se dedica a promover su uso y preservación, lo cual es muy útil para generar propuestas de políticas lingüísticas en países multilingües (Bastardas-Boada 2002).

Como ciencia, la ecolingüística se originó a través de la aplicación de analogías y de metáforas transdisciplinarias, extrapoladas desde el campo de la ecología hacia el campo de la lingüística; como señala Holland (1998), la exploración de otras filosofías y campos conceptuales suele contribuir a producir nuevas ideas valiosas para ser aplicadas en diferentes problemas de la realidad. Además de la ecología y la biología, la ecolingüística, constituida como una transdisciplina, recibe contribuciones desde varias escuelas y ramas de las ciencias 
socioculturales - desde sociología cognitiva hasta ciencias políticas y jurídicas. Inspirada en las analogías de otras disciplinas y manteniendo su integración con ellas, la ecolingüística tiene la posibilidad de producir nuevos paradigmas, abriendo vías para un mejor entendimiento de los fenómenos lingüísticos y sociales.

Dadas las similitudes aparentes entre la diversidad biológica y la diversidad lingüística, como también la naturaleza simultánea de estos dos fenómenos, ambos de carácter global, resulta pertinente comparar algunas ideas y categorías del campo de la biología con las del campo de la lingüística, tomando en cuenta que un mejor desarrollo de la conceptualización teórica se presenta en el primero.

A primera vista, los objetos de estudio de la biología y de la lingüística son muy diferentes: por un lado, se trata de las especies biológicas ubicadas en el seno de la naturaleza, por el otro, de las variedades lingüísticas enclavadas en el ámbito de la cultura. La diversidad biológica es producto de la evolución, mientras que la diversidad lingüística se debe a las vicisitudes socio-cognitivas y experimentales del ser humano. Los objetos biológicos son controlados por el código genético y la biosfera; los objetos lingüísticos están influenciados por las experiencias socioculturales de sus hablantes. En su lucha por la sobrevivencia, los objetos biológicos son afectados por su ambiente natural; los sistemas linguiísticos, además del ambiente, son afectados por las condiciones socioeconómicas y político-culturales de las sociedades respectivas. Por último, los protagonistas de la reproducción de la diversidad biológica no poseen voz propia, mientras que en el proceso de la reproducción y preservación de la diversidad lingüística, los seres humanos están capacitados para tomar decisiones en cuanto a la continuidad o desaparición de la diversidad. Es decir, las leyes naturales no se pueden evitar, mientras que las reglas sociales, generadas en el sistema sociocultural y frecuentemente codificadas en leyes, pueden romperse, otorgando más autonomía a los humanos respecto a decisiones a tomar acerca de su comportamiento lingüístico-cultural.

A pesar de estas diferencias, la ecología y la lingüística coinciden en que los objetos de estudio de ambas son entidades interrelacionadas multidimensionalmente con su contexto, bien sea natural o geodemosociopolítico: en ambas ciencias, se hace énfasis en el todo más que en las partes, y tanto las especies naturales como las lenguas se presentan como redes de relaciones incrustadas en redes de relaciones mayores (Capra 1997). En este sentido, los objetos naturales y lingüísticos son eventos y procesos dinámicos, cuya evolución es, en esencia, una coevolución (Bastardas-Boada 2002; Mosonyi 2003), donde una parte del sistema evoluciona de manera interdependiente con otras partes, dentro de su propio ambiente.

Este parentesco esencial entre la ecología y la lingüística se revela también en la existencia de un número importante de metáforas ecológicas, las cuales abundan en el campo de la ecolingüística. Se habla del "ambiente" linguiístico, de idiomas "amenazados" o "en peligro de extinción", de la "muerte" de las lenguas o de su "sostenibilidad en el tiempo". También provienen de este campo los conceptos de población y comunidad, muy importantes para la ecolingüística, refiriéndose el primero a un grupo específico de personas con la misma primera lengua y el segundo, a aquellas sociedades formadas por grupos con diferentes primeras lenguas y con un grado de mutua influencia y adaptación (Bastardas-Boada 2002).

\section{Origen, evolución y mantenimiento de la diversidad lingüística de Venezuela}

Venezuela es un país con una gran diversidad lingüística: en un territorio de un poco más de 900 mil kilómetros cuadrados, se hablan alrededor de 100 lenguas diferentes, a pesar 
de la predominancia absoluta del español. ¿Cómo se originó esta diversidad lingüística en Venezuela? ¿Cómo ha evolucionado en el tiempo?

Según Bastardas-Boada (2002), la distribución geográfica de las agrupaciones humanas ejerce una influencia fundamental en la producción y existencia de la diversidad. Antes de la llegada de los colonizadores españoles, convivían en el territorio venezolano más de cien lenguas indígenas (Mosonyi 2007). El número de sus hablantes estaba sujeto principalmente a las consecuencias de las guerras inter-tribales y los contactos comerciales o familiares entre las etnias que se encontraban en un relativo aislamiento lingüístico. Sin una comunicación a gran escala entre ellas, los grupos lingüísticos se desenvolvían cada cual a su manera, acorde a sus características y propiedades, desarrollando variedades de comunicación específicas para cada grupo; a través de varias generaciones, estas formas de comunicación evolucionaban dinámicamente, profundizando la diversidad.

A partir de la época de la colonización, se introduce en el contexto lingüístico originario del país un elemento extraño, el cual se vuelve cada vez más y más agresivo: el español. Esta lengua se implanta en Venezuela y se desarrolla tímidamente al principio, coexistiendo con las lenguas indígenas mucho más numerosas, para luego subordinarlas y desplazar parcial o totalmente la gran mayoría de ellas. Cabe destacar que el español de Venezuela tampoco constituye un fenómeno lingüístico homogéneo por presentar variedades y dialectos geográficos y sociales dentro de su propia estructura.

Con la intensificación del fenómeno de la inmigración, sobre todo, en el siglo XX, surgen en el país numerosos grupos lingüísticos trasplantados que entran de inmediato en contacto tanto con el español como con las lenguas indígenas (aunque en menor grado). Desde entonces, estos tres grupos de lenguas han interactuado y en la actualidad coexisten lado a lado, formando la tríada lenguas indígenas-español-lenguas de las diásporas extranjeras, interactuando a diario e influenciando las unas a las otras.

Actualmente, todas estas lenguas están coevolucionando en el mismo espacio geográfico, en conjunto con los eventos demográficos, socioeconómicos, políticos y tecnológicos que se van produciendo en la sociedad. De esta manera, se puede afirmar que la diversidad ecolingüística venezolana actual está basada en la autopoiesis, (término acuñado por Varela, Maturana y Uribe 1974) o autoorganización, y es producto de las interacciones histórico-sociales de los individuos pertenecientes a estos tres elementos lingüísticos, fruto de las subordinaciones políticas y movimientos migratorios y resultado de la historia sociolingüística de Venezuela.

¿Cómo se ha mantenido la diversidad linguiística del país en el tiempo? En términos generales, esta continuidad está relacionada con el contexto demo-socio-cultural del país. El primer factor que influye en la continuidad lingüística de las lenguas venezolanas es la sobrevivencia física de sus hablantes: mientras que estén vivos, la lengua sigue viva. La exterminación física de los integrantes de las etnias indígenas durante la época de la colonización, condenada posteriormente, resultó en el declive y desaparición para siempre de más de setenta lenguas indígenas que existían en el territorio venezolano antes del siglo XVI. En nuestra época, la desaparición física de los hablantes de algunas de estas etnias es factor importante de la desaparición de la respectiva lengua. Así por ejemplo, la lengua sapé está en peligro de desaparición porque tiene tan sólo seis hablantes ancianos. Además, todos ellos son bilingües sapé-español. Una situación similar enfrenta la lengua arutani, llamada también uruak, ya que a pesar de ser esta etnia monolingüe en un 95\%, tiene tan sólo 39 hablantes, también personas mayores. 
Pero el concepto clave que influye drásticamente en el mantenimiento o discontinuidad de la diversidad lingüística es el contacto lingüístico. Mientras que un grupo lingüístico vive en su propio hábitat sin la presencia de otras comunidades lingüísticas que puedan competir con él, la continuidad de la lengua está garantizada. Es por esta razón que los pueblos indígenas con escasos contactos con los criollos, tales como los yanomamis, los sanemá, los arutani o los jodi, son monolingües en su mayoría (los yanomamis son monolingües en un 92\%, los sanemá en un 93\%, los autani en un 95\% y los jodi en un 98\%) (XIII Censo General de Población y Vivienda 2001). De los 767 jodi, por ejemplo, 752 personas solamente saben hablar la legua jodi y tan sólo 15 personas son bilingües jodi-español. Esta etnia ha sido muy escasamente estudiada precisamente por haber tenido contactos mínimos con los criollos. Estos datos indican que para garantizar la continuidad lingüística, debe existir un alto nivel de relaciones intra-grupo y un nivel bajo de relaciones inter-grupo.

En contraste, contactos prolongados entre los hablantes del español y los de las lenguas indígenas condujeron a la existencia de etnias enteras que conservan sus rasgos culturales aunque hayan perdido su lengua, desplazada por el español. Este es el caso de las etnias añú (de sus 11.205 integrantes, 11.194, o 99\%, son hispanohablantes y tan sólo 11 son bilingües añúespañol). Otros ejemplos similares son los mapoyo (hispanohablantes en un 89\%) y los kariña (hispanohablantes en un 63\%) (XIII Censo General de Población y Vivienda 2001). A veces sucede que un idioma indígena se debilita por un contacto con otra lengua indígena y no con el español; así por ejemplo, el yavarana está a punto de desaparecer, absorbido por el piaroa, debido a una gran cantidad de matrimonios enrte los yavarana y los piaroa (Mosonyi 2007).

En algunos casos, los contactos interlingüísticos son multilaterales y de esta manera las influencias lingüísticas se vuelven aún más complicadas. Así por ejemplo, de acuerdo con Mosonyi (2007), muchos de los integrantes de la etnia akawayo son trilingües akawayoespañol-inglés, como también lo son los integrantes de la etnia ñengatú (ñengatú-españolportugués) y piapoco (piapoco-jivi-español).

En cuanto a las comunidades extranjeras, estas disminuyen la cantidad de sus hablantes en la segunda y aún más en la tercera generación precisamente por el aumento de contactos, o una mayor integración, con la sociedad receptora. Un buen ejemplo de ello es la situación lingüística de la Colonia Tovar, ubicada a $42 \mathrm{~km}$ de la ciudad de Caracas, donde residen los descendientes del contingente de los inmigrantes alemanes que llegaron a Venezuela en 1843: en sus primeros 100 años de existencia (1843-1943), sus habitantes vivieron en un aislamiento total del resto del país, el $100 \%$ de la población hablaba el dialecto alemánico y la transmisión de su lengua materna a las nuevas generaciones era total. Sólo a mediados del siglo pasado, cuando la Colonia se abrió al mundo externo, empezaron sus contactos con los hablantes del español, aumentándose paulatinamente, lo cual, aunado a la campaña de desprestigio del idioma desatada por las autoridades venezolanas, repercutió de inmediato en la situación del idioma y actualmente, este se encuentra en peligro de desaparecer.

\section{Contacto lingüístico: antecedentes, consecuencias y clasificación}

La diversidad lingüística venezolana se encuentra y se reproduce dentro de la dinámica ecológica. Las poblaciones y las comunidades lingüísticas pasan por cambios cuantitativos y cualitativos en su composición, alternándose los procesos de expansión y de contracción. En cada lengua, procesos de cambios y de relativa estabilidad se alternan en un flujo continuo e interrelacionado. Como resultado de la evolución de la diversidad, se producen nuevas formas y 
variedades, como por ejemplo el alemán coloniero que solamente se habla en la Colonia Tovar y resulta incomprensible para un oriundo de Alemania. Por otro lado, esta misma evolución de la diversidad puede terminar en la desaparición sin rastros de lenguas, como ha sido el caso de los idiomas indígenas el timote, el chaima o el yavitero.

Aunque muchas veces el contacto lingüístico resulta en una especie de simbiosis, o coexistencia pacífica de lenguas, el contacto entre poblaciones que hablan lenguas diferentes generalmente tiende a terminar en la extinción de una de ellas.

El proceso de extinción empieza con un contacto con otra(s) lengua(s); este se puede definir como perturbación. Si la interacción entre diferentes grupos lingüísticos es muy intensa, la perturbación conlleva a que el grupo con la lengua más débil adopte paulatinamente la lengua del grupo dominante. Tal ha sido el caso de la mayoría de las lenguas indígenas en contacto con el español, desde la época del auge del desarrollo industrial del país. Encontrándose los indígenas en condiciones de inferioridad numérica y subordinación cultural, sus contactos lingüísticos con la población criolla terminan en que éstos empiecen a experimentar vergüenza étnica, fruto de ideología aculturativa, y adopten actitudes de desprecio por sus raíces y sus lenguas, por carecer estos de prestigio y de reconocimiento social. En el caso de los wayuu, por ejemplo, los representantes de este pueblo "[...] han recibido educación universitaria y muchos han aprendido a no ser como sus padres y sus abuelos" (Pérez 2004: 628).

Sin embargo, en la mayoría de los casos, la extinción de las lenguas es causada por la combinación de dos factores: contacto lingüístico más el proceso demográfico de disminución del número de hablantes. La lengua demoraría en extinguirse si el caso se limitara a un solo factor, bien sea el declive demográfico o el contacto con una lengua más poderosa; la presencia de ambos factores a la vez acelera la desaparición de la lengua.

A su vez, los contactos intensos entre grupos lingüísticos pueden ocurrir en el contexto de la subordinación socio-política, como es el caso de las lenguas indígenas en contacto con el español, o en el contexto de los movimientos migratorios, como es el caso de las diásporas extranjeras que hacen vida en el territorio venezolano. En este último caso, se afectan tanto los sistemas lingüísticos que reciben a los inmigrantes, como el sistema lingüístico importado. En su mayoría, los inmigrantes se integran a su nuevo ambiente y asimilan los comportamientos lingüísticos de la población receptora, abandonando su lengua materna; sin embargo, puede haber casos de equilibrio dinámico en el cual cada grupo lingüístico mantiene el número de sus hablantes, como por ejemplo las comunidades china y árabe en Venezuela.

Por otro lado, se presentan situaciones que involucran comunidades que ocupan un territorio específico en el cual la presencia de elementos lingüísticos externos es limitada. Esta situación podría llamarse contacto lingüístico vertical y se caracteriza por una definida distribución de las funciones entre las lenguas en contacto. En el contacto lingüístico vertical, las comunicaciones locales se llevan a cabo en la lengua autóctona, mientras que las comunicaciones exteriores se realizan en la lengua dominante (el español). Tal es el caso de la mayoría de las lenguas indígenas, ya que todavía no se encuentran diluidas entre la población mayoritaria de habla española. El wayuu, por ejemplo, no entra en esta categoría, puesto que una gran cantidad de hablantes de esta lengua vive en la ciudad de Maracaibo, mezclada con la población criolla. El alemán coloniero, a pesar de su relativo aislamiento geográfico, difícilmente clasificaría como en situación de contacto lingüístico vertical por estar mudándose una importante cantidad de caraqueños y gentes de otras localidades a la Colonia Tovar, produciendo una mezcla de la población (Primera 2007). 
Otro tipo de situaciones se podrían etiquetar como situaciones de contacto lingüístico horizontal, cuando poblaciones con diferentes lenguas maternas comparten el mismo espacio geográfico, como lo hacen por ejemplo, los inmigrantes italianos o portugueses en las grandes ciudades del país. Estas personas están esparcidas por todo el territorio nacional, conviviendo día a día con la población criolla. Sin control suficiente sobre su vida pública, muchos de estos grupos minoritarios no tienen condiciones para mantener su lengua.

\section{Distribución funcional como factor decisivo para estimar la continuidad de las lenguas minoritarias}

Cuando los contactos lingüísticos son inevitables y/o irreversibles y los integrantes de la comunidad presentan diferentes grados de bi- o multilingüismo, el elemento clave para estimar la continuidad lingüística es la distribución funcional de las lenguas involucradas y la evolución histórica de esta. En otras palabras, para determinar las condiciones mínimas requeridas para que un grupo lingüístico en situación de contacto permanezca en el tiempo, sería necesario examinar el uso funcional que se dé a la lengua propia del grupo y a la lengua exógena y garantizar un balance en la distribución de las funciones desempeñadas por ambas. Esto, a su vez, depende de las convenciones sociales establecidas en el grupo.

En primer lugar, el uso de la lengua debe ser gobernado por las prácticas habituales del grupo y no por restricciones forzadas o imposiciones. Una de las vías para aplicar este principio es promover el uso de la lengua en recesión para funciones exclusivas específicas dándole la posibilidad de retornar a su funcionalidad normal, aunque no se use para expresar todos los intercambios comunicativos de la comunidad respectiva. Sin estas funciones exclusivas, la lengua se tornará, inevitablemente, dispensable y rápidamente se extinguirá. Si la lengua es funcional y si se usa regularmente, sus hablantes tendrán una mayor motivación para transmitirla a las nuevas generaciones, las cuales ya no la conceptualizarían como una reliquia del pasado sino como aspecto indispensable de su comportamiento lingüístico habitual.

Actualmente, son las lenguas indígenas las que más funciones desempeñan en Venezuela, seguidas por el italiano y el portugués, con 5 funciones cada una. En cuanto al árabe y chino/alemán coloniero, estas lenguas desempeñan 4 y 3 funciones, respectivamente, tal como se evidencia del siguiente cuadro, tomado de Bondarenko (2010):

Cuadro 2. Distribución funcional de las lenguas minoritarias de Venezuela

\begin{tabular}{|l|c|c|c|c|c|c|c|}
\hline \multirow{2}{*}{ Lengua } & \multicolumn{7}{|c|}{ FUNCIONES DESEMPEÑADAS } \\
\cline { 2 - 8 } & nacional & oficial & $\begin{array}{l}\text { de los medios de } \\
\text { comunicación }\end{array}$ & grupal & educacional & como asignatura & literaria \\
\hline $\begin{array}{l}\text { Lenguas } \\
\text { indígenas }\end{array}$ & $\sqrt{ }$ & $\sqrt{ }$ & $\sqrt{ }$ & $\sqrt{ }$ & $\sqrt{ }$ & $\sqrt{ }$ & $\sqrt{ }$ \\
\hline Italiano & $\sqrt{ }$ & $\times$ & $\sqrt{ }$ & $\sqrt{ }$ & $\times$ & $\sqrt{ }$ & $\sqrt{ }$ \\
\hline Portugués & $\sqrt{ }$ & $\times$ & $\sqrt{ }$ & $\sqrt{ }$ & $\times$ & $\sqrt{ }$ & $\sqrt{ }$ \\
\hline Árabe & $\sqrt{ }$ & $\times$ & $\sqrt{ }$ & $\sqrt{ }$ & $\times$ & $\sqrt{ }$ & $\times$ \\
\hline Chino & $\sqrt{ }$ & $\times$ & $\times$ & $\sqrt{ }$ & $\times$ & $\sqrt{ }$ & $\times$ \\
\hline $\begin{array}{l}\text { Alemán } \\
\text { coloniero }\end{array}$ & $\sqrt{ }$ & $\times$ & $\times$ & $\sqrt{ }$ & $\times$ & $\sqrt{ }$ & $\times$ \\
\hline
\end{tabular}


En el caso hipotético de que se publicaran en Venezuela libros y periódicos en árabe o chino, o que existieran programas de televisión en estos idiomas, este aumento de su funcionalidad repercutiría en su consolidación inmediata. Y si existieran en el país instituciones educativas donde la enseñanza se llevara a cabo en estos y otros idiomas minoritarios, la supervivencia de estas lenguas estaría garantizada. En fin, la asignación de un número máximo de funciones es vital para la conservación de la lengua.

Pero aún con esta distribución de funciones, poblaciones bi- o multilingües no necesariamente van a perder su propia lengua, siempre y cuando se mantenga una clara distribución funcional que le asigne funciones exclusivas. En este caso, aunque el grupo maneje otras lenguas, esas se reservan para uso externo o para alguna función específica claramente establecida. Así por ejemplo, los integrantes de las comunidades extranjeras, para preservar su lengua, la hablan en casa con sus hijos y demás familiares, ven programas en su idioma materno por la televisión satelital o por cable, la usan en reuniones intragrupales, la estudian como asignatura, inclusive, rezan en su lengua propia, relegando el español a los contactos con la población criolla y toda clase de diligencias administrativas o legales que deben atender en su nuevo país de residencia.

De igual modo, los pueblos indígenas que habitan zonas de difícil acceso, usan su lengua para todos los efectos en su vida cotidiana, mientras que el español entra en el juego cuando los representantes de la etnia requieran de tratar asuntos con los no-indígenas.

\section{Intervención ecolingüística}

El grupo lingüístico y su hábitat respectivo forman la unidad básica de la existencia. Las lenguas, por lo tanto, no son otra cosa que lenguas-en-su-contexto; el primer y principal contexto de las lenguas lo constituyen las personas que las transportan; ellas, a su vez, están inmersas en su contexto natural, como también en un ambiente político, económico, demográfico y sociocultural específico. Mientras que este hábitat multidimensional que dio origen a una forma particular de comunicación permanezca estable, la continuidad de una lengua ocurre naturalmente y esta se reproduce automáticamente de generación en generación. $\mathrm{Si}$, por el contrario, se producen alteraciones en cualquier dimensión de su ambiente, la reproducción intergeneracional puede llegar a ser comprometida y las lenguas pueden llegar a ser reemplazadas por otras.

En nuestros días, muchas etnias cuyas lenguas históricas han desaparecido o están desapareciendo, lamentan profundamente la pérdida de su lengua y quisieran recuperar sus códigos comunicacionales ancestrales, como es el caso de los chaimas, los kuivas o los descendientes de los colonos alemanes. En ausencia de un contexto natural para el mantenimiento de la lengua, el énfasis se haría en promover el desarrollo de la lengua creándole condiciones que esta podría esperar de un contexto natural para poder funcionar eficazmente. Para preservar y recuperar las lenguas en vía de extinción, asegurando la viabilidad ecolingüística de los grupos minoritarios, son necesarias medidas de intervención ecolingüística. En este sentido, es vital que las comunidades lingüísticas que hoy se encuentran en recesión, introduzcan cambios mayores en su organización social y promuevan la recuperación de las funciones que solían desempeñar sus lenguas extintas o amenazadas, ya que a la larga, son las funciones comunicativas cotidianas en la comunidad las que de manera natural otorgan la continuidad y la funcionalidad a las lenguas. 
Para decidir qué acción es la más apropiada para una oportuna intervención ecolinguiística, habría que estudiar las causas del contacto lingüístico y la situación general de la comunidad investigada; de igual manera, las dinámicas de acción y las medidas serían diferentes si se tratase de contactos causados por subordinación política o producidos por movimientos migratorios. Los casos más fáciles de resolver son los que involucran un contacto lingüístico vertical; más difíciles son las situaciones de contacto lingüístico horizontal.

En todo caso, la intervención restaurativa con la finalidad de recuperar la lengua debe ser conducida desde una perspectiva holística. Antes de emprender cualquier acción, habría que determinar: (a) el carácter del contacto lingüístico, (b) qué funciones son fundamentales para la lengua minoritaria y qué funciones pueden ser relegadas a la lengua dominante, y (c) cómo los cambios por introducir podrían interactuar con otros cambios sociales en marcha. De allí, es notorio que la intervención ecolingüística no es un acto puramente lingüístico, sino que está interconectado con los impactos de las medidas económicas, políticas, educativas y de otras índoles. De igual manera, la intervención ecolingüística requeriría diferentes acciones dependiendo del grado del desarrollo técnico-industrial del grupo lingüístico minoritario, las dinámicas de su población y la imagen colectiva que proyecta.

Una intervención ecolingüística podría consistir en: (a) promover la ideología de la equidad y solidaridad lingüística, (b) dignificar la autoimagen de los grupos lingüísticos minoritarios, (c) permitir que los grupos lingüísticos controlen su propio espacio comunicativo, (d) distribuir las funciones comunicativas, asignando funciones exclusivas a los grupos subordinados o (e) concientizar a la población en torno a la importancia de preservar la lengua.

Generalmente, los grupos lingüísticos que abandonan sus lenguas no ejercen control sobre su vida colectiva, no están lo suficientemente desarrollados económicamente, experimentan una movilidad geográfica y/o social y tienen una autoimagen desfavorable. Por otro lado, el abandono de la lengua autóctona es mucho menos frecuente en grupos que controlan su vida colectiva, tienen un buen desarrollo económico, viven en un solo territorio y mantienen una autoimagen positiva (Bastardas-Boada 2007). El rompimiento del balance bilingüe ocurre cuando un número importante de individuos del mismo grupo lingüístico empieza a usar la lengua dominante de manera masiva y la traspasa al ámbito individual y doméstico -a partir de este momento, el sistema lingüístico entra en crisis.

Sin embargo, hay que recordar que no se puede obligar a un grupo humano mantener o cambiar su comportamiento lingüístico particular sin su consentimiento y su participación voluntaria y activa. Desde el punto de vista de la ética sociolingüística y tomando en cuenta la equidad e igualdad de todas las lenguas en su derecho de existir, no se puede olvidar la autonomía, la participación y el compromiso de los agentes sociales involucrados. En este sentido, es de vital importancia el principio de la autodeterminación, cuando los propios grupos lingüísticos minoritarios deciden qué lengua o lenguas deben hablar, resolviendo el dilema de utilidad o identidad. Esto implica que en el nivel político, las medidas deben ser aceptadas por medio de procedimientos democráticos y participativos.

El éxito de una intervención ecolingüística dependerá del análisis adecuado de la situación de la lengua y de la prontitud de las acciones; no hay que olvidar que la intervención ecolinguiística es muy diferente de la biológica, ya que su punto de partida es la capacidad mental de los seres humanos para considerar la posibilidad de resistir las presiones del contexto desfavorable e intentar modificarlo a su favor. A diferencia del contexto biológico, en el contexto humano el grado del determinismo es menor y la posibilidad de redireccionar 
o revertir un proceso sociocultural es mucho más grande. Los individuos, a diferencia de los animales, son capaces de analizar el contexto en términos dinámicos y cambiar su realidad.

\section{Hacia una sostenibilidad ecolingüística en Venezuela}

La idea de sostenibilidad proviene del pensamiento que critica la perspectiva del desarrollo económico que no presta atención al medio ambiente. Como concepto, sostenibilidad surge a finales de los 1980 y es reconocido mundialmente en la conferencia de las Naciones Unidas en Río de Janeiro en 1992 (Bastardas-Boada 2007). En el documento titulado "Reporte de Bruntdland", se define como forma de desarrollo sostenible que satisface las necesidades del presente sin comprometer la capacidad de las futuras generaciones de satisfacer sus propias necesidades.

Al transferir esta manera de pensar a la problemática ecolingüística, se abre la posibilidad de reconciliar dos tendencias opuestas, una de las cuales aboga por el abandono de las lenguas originarias en pro de las lenguas dominantes en expansión y la otra que está a favor de la preservación de la diversidad lingüística humana y el mantenimiento de las distintas identidades colectivas. Estas perspectivas, irreconciliables y antagónicas a primera vista, se pueden reconciliar dentro del pensamiento ecolingüístico, revirtiendo las ideologías expansionistas, poniendo fin a la jerarquía de valores inspirada en las creencias de inferioridad/superioridad de las lenguas y reconociendo la dignidad de todas ellas y de los grupos lingüísticos correspondientes.

La sostenibilidad ecolingüística hace un llamado a la continuidad y desarrollo pleno de los grupos lingüísticos, sin destruir los recursos lingüísticos y culturales que los identifican. La ecolingüística, como ciencia, promueve valores de conservación, cooperación, calidad y compañerismo, y desde el punto de vista de la ética de la sostenibilidad, la diversidad lingüística es un valor que merece ser protegido.

El aspecto crucial que deriva del enfoque de la sostenibilidad es que el bilingüismo siempre precede el abandono de la lengua original. Sin embargo, el bilingüismo es una condición necesaria pero no suficiente para el desuso de la lengua. El factor primordial es el contexto político y las actitudes lingüísticas que de él resultan.

Un contacto lingüístico sostenible es aquel que no produce una exposición a la lengua dominante o uso de esta lengua en un grado tan alto como para volver imposible la continuidad de la lengua minoritaria. El carácter sostenible de un bilingüismo masivo se puede estimar por medio de la comparación entre la valoración y las funciones desempeñadas por la lengua minoritaria y la lengua dominante: si la primera es mayor, el bilingüismo es sostenible; si es menor, la lengua minoritaria desaparecerá en pocas décadas.

En la época de la globalización y de los contactos crecientes entre la población indígena, población criolla y comunidades de extranjeros que hacen vida en Venezuela, se incrementa la difusión de las fronteras culturales y lingüísticas entre ellas. En cuanto a los indígenas, algunos autores (e.g. Mosonyi y Pocaterra 2004) afirman que en Venezuela se logra ganar la batalla por el desarrollo sostenible de los pueblos indígenas con sus identidades propias, porque aún siendo pueblos pequeños, son pueblos sólidos y en un futuro estos pueblos “[...] seguirán existiendo en forma indefinida, es decir sin estar sujetos a la amenaza permanente de la extinción física o identitaria [...]" y serían "[...] culturas modificadas pero con un sello de identidad peculiar" (Mosonyi y Pocaterra 2004: 6). Esto 
se refiere, antes que nada, a la etnia yanomani, “[...] uno de los aislados sociales más conspicuos de la humanidad" (Mosonyi y Pocaterra 2004: 6), considerada patrimonio de la humanidad por su considerable antigüedad (Mosonyi 2007), que se apoya en la espina dorsal de unos 30 - 50 mil años de historia. Igualmente, Serrón (2007b) piensa que la visión pesimista acerca de la desaparición de las lenguas indígenas ya quedó superada. Al respecto, Mosonyi comenta sarcásticamente que "[...] incluso hay gente que todavía piensa que las culturas y lenguas indígenas - dado el fenómeno de la globalización - están a punto de extinguirse y que su ocaso es inevitable. Nada más lejos de verdad" (2003: 52). En cuanto al desplazamiento de los idiomas indígenas por los grandes sistemas lingüísticos dominantes, este autor opina que "[...] los indicadores positivos existen y tienen mucho pero en el acontecer mundial actual” (2003: 31) y que "el número de lenguas indígenas existentes en Venezuela así como el número de sus hablantes, lejos de disminuir, van en constante aumento" (2003: 19). Crystal (2001: 66) también señala que "pese a todas las amenazas que pesan sobre los pueblos indígenas, aún representan una quinta parte de la superficie de la tierra”. Sin embargo, de acuerdo con Mosonyi y Pocaterra (2004), las lenguas sucumben más rápidamente que las identidades, por lo tanto, las interrogantes ¿qué idioma o idiomas hablarán estos pueblos neoindios? y ¿hablarán en su propio idioma o se plegarán a algún idioma mayoritario?, quedan aún sin respuesta.

Las razones de la preocupación por la pérdida de las lenguas radican en uno de los principios básicos de la ecolinguiística. Desde el punto de vista de esta ciencia, los argumentos que abogan por la necesidad de una diversidad biológica también aplican al lenguaje. Callenbach (1999: 22) opina que "buena parte de la belleza de este mundo proviene de su espléndida profusión de vida”. Crystal (2001) afirma que en el lenguaje de la ecología, los ecosistemas más fuertes son los más diversos y la variedad puede ser una necesidad en la evolución de los sistemas naturales. La misma idea la expresa Esté (1999: 47), señalando que "la diversidad es causa de la riqueza humana", y que "[...] la diversidad supone diferentes culturas y perspectivas que se considere necesario conservar y discutir para que haya justicia y enriquecimiento humano" (1999: 170). Lárez et al (1996: 120). aseveran que "[...] el aporte lingüístico [...] de los grupos indígenas no se puede soslayar porque es parte de nuestro patrimonio sociocultural". Delahaye (1979) desarrolla la misma idea, señalando que nuestros idiomas indígenas merecen toda nuestra atención por su cualidad de portadores de culturas milenarias únicas e insustituibles cada una, y por su valor - siempre creativo, estético y expresivo-. El argumento de Mosonyi y Pocaterra, por otro lado, es aún más drástico; ellos opinan que "de los conocimientos atesorados por estas lenguas, hoy minorizados, depende [...] la supervivencia del planeta" (2004: 22). Además, cada uno de estos idiomas representa un inmenso valor estético y humano, tanto en sí mismo como en conexión con la cultura respectiva. Suponiendo, por ejemplo, que el idioma wayuunaiki desapareciera, la humanidad seguiría hablando a través de otros sistemas lingüísticos pero ninguno sería igual a wayuunaiki, cuya fonología también comprende vocales y consonantes pero articuladas e interconectadas de un modo irrepetible, de manera que "[...] la red asociativa que reúne y preside todos estos rasgos solo se da en esta lengua y las leyes de posibilidades impiden que jamás se produzca nada similar" (Mosonyi 2003: 16). Por estas razones, conservar las lenguas indígenas y todas las demás que se hablan en el país, significa conservar la sabiduría y la diversidad.

Sin embargo, como señala Brünner, aunque la globalización es percibida por parte de las comunidades indígenas como amenaza, sorprendentemente, este fenómeno está 
transformando las relaciones entre el centro y la periferia, provocando "una nueva presencia de las civilizaciones olvidadas/excluidas al interior de las propias culturas de los países industrializados" (1999: 157).

La desaparición de las lenguas indígenas, sin duda alguna, no se producirá ni hoy ni mañana; como afirma Crystal (2001), la muerte de las lenguas es un proceso gradual y complejo: no se puede inscribir una única causa en el certificado de su defunción; solo la propia comunidad indígena puede salvar su lengua, junto con los esfuerzos organizados de la intervención ecolingüística preventiva, una fuerte representación en el sistema educativo y la utilización de la tecnología electrónica.

Mosonyi (2003: 23) opina, con optimismo, que "[...] la creatividad de los pueblos indígenas inventará seguramente en los próximos años muchas fórmulas novedosas para mantener y acrecentar el uso de sus lenguas y crear en forma continua nuevos espacios interculturales" y "[...] el deterioro es casi siempre reversible" (2003: 22). En este sentido, un factor muy importante de conservación de un idioma es el fomento de su literatura y presentando mensajes en idiomas indígenas en la industria mediática, en los lugares públicos y en las calles. Esto lo hacen los dirigentes responsables del movimiento indígena, fundamentando el proceso de revitalización lingüística de su etnia. Cada comunidad debe iniciar su propia acción contando consigo mismo y con la asesoría de los asesores competentes: "los signos positivos son estimulantes en la medida de que los pueblos indígenas y sus aliados trabajen duramente, con disciplina y tesón inquebrantables, en pos de su recuperación cultural y lingüística" (Mosonyi 2003: 19).

En cuanto a las lenguas de las diásporas extranjeras que hacen vida en el territorio venezolano, éstas no cuentan ni con el respaldo constitucional, ni con el apoyo o protección formal alguna por parte del Estado, pero forman parte del espacio lingüístico venezolano y participan en su desarrollo. En este sentido, sin aportes migratorios importantes (y los mismos no se prevén en el futuro próximo en Venezuela), las lenguas de las diásporas tenderán a mermar y si las comunidades respectivas no tomen conciencia de esta situación y no adopten medidas inmediatas para la consolidación de su herencia lingüístico-cultural, sus lenguas maternas desaparecerán del territorio venezolano de manera inevitable. En este sentido, son los propios miembros de estas comunidades, con la ayuda de los proyectos gubernamentales y algunas empresas privadas, que toman la iniciativa y se organizan en asociaciones para poder hacer valer su cultura y su lengua, resaltando la educación como centro de acciones y punto de partida.

En fin, para conservar las lenguas amenazadas, hace falta algo más que un simple acto de "tozudez colectiva" (Mosonyi 2003: 15): es perentorio armonizar el desarrollo económico, la comunicación intercultural y el mantenimiento de las lenguas; a la larga, la sostenibilidad o la no sostenibilidad de una lengua no depende de la lengua misma, sino del sistema sociocultural general en el cual se encuentra y de otros elementos de la realidad.

\section{Conclusión}

La diversidad lingüística de Venezuela se constituye a través de tiempo como producto de los procesos históricos de subordinación socio-política (colonización) e integración internacional (inmigración) y ha evolucionado en función del desarrollo del contexto demosocio-cultural del país. Los contactos lingüísticos, tanto de carácter vertical como horizontal, son factores decisivos que han influenciado el mantenimiento o la discontinuidad de las lenguas 
minoritarias de Venezuela, resultando, en algunos casos, en la coexistencia pacífica de lenguas. Cuando los contactos lingüísticos se vuelven inevitables y frecuentes, el elemento clave para estimar la continuidad de la lengua minoritaria es la distribución funcional de usos, y cuando la lengua está a punto de desaparecer o se encuentra extinta, la intervención ecolingüística se presenta como medida destinada a recuperar el respectivo código comunicacional. Sin embargo, es el propio grupo lingüístico minoritario el que debe tomar el control sobre la decisión en cuanto a la lengua que quiere hablar.

Finalmente, para un país multilingüe como Venezuela, el modelo de sostenibilidad se ofrece como una oportunidad para el mantenimiento lingüístico, por el camino de la equidad y justicia sociolingüística. La solución ya no consiste en subsidiar a las lenguas, sino adoptar posiciones más progresivas e igualitarias, donde sólo los grupos lingüísticos que inicien acciones compensatorias y rebalanceadoras en sus sistemas ecolingüísticos, podrán seguir reproduciéndose de manera sostenible.

\section{Bibliografía}

Bastardas-Boada, Albert. 2002. Biological and linguistic diversity. http://www.teluq.uquebec. ca/diverscite/SecArtic/Arts/202/bastarda/txt.htm._Consulta: 12 de febrero de 2010.

2007. "Linguistic sustainability for a multilingual humanity". Glossa. 2 (2). http:// bibliotecavirtualut.suagm.edu/Glossa2/Journaljun2007/Vol2num2.htm. Consulta: 15 de diciembre de 2009.

Bolívar, Simón. 1819/1975. Discurso de Angostura. Caracas: Presidencia de la República.

Bondarenko, Natalia. 2010. Lenguas minoritarias en el contexto educativo venezolano contemporáneo. Tesis Doctoral: Universidad Pedagógica Experimental Libertador.

Brünner, José Joaquín. 1999. Globalización cultural y posmodernidad. Santiago de Chile: Fondo de Cultura Económica.

Callenbach, Ernest. 1999. La ecología. Madrid: Siglo XXI de España.

Calvet, Louis-Jean.1999. Pour une écologie des langues du monde. Paris: Plon.

Capra, Fritjof. 1997. The Web of Life. London: Flamingo.

Crystal, David. 2001. La muerte de las lenguas. Madrid: Cambridge University Press.

Delahaye, Marieke. 1979. Lenguas indígenas en el proceso educativo: educación intercultural bilingüe. Ponencia para el "Primer Seminario de Indigenismo y Lingüística". Caracas, 15-24 de febrero.

Dil, Anwar S. 1972. Essays by Einar Haugen. Stanford: Stanford University Press. 
Esté, Arnaldo. 1999. Migrantes y excluidos. Caracas: Universidad Católica Andrés Bello.

Haugen, Einar. 1972. The Ecology of Language. En: A.S. Dil (ed.), 325-339.

Holland, John. 1998. Emergence from chaos to order. Cambridge, MA: Perseus Publishers.

Lárez, Ronald, Alberto Muñecas y Renán Golindano. "Propuesta educativa aplicable a los grupos étnicos Kariña y Warao de Venezuela". Encrucijada Educativa. 2: 113-131.

Mosonyi, Esteban Emilio. 2003. Temas de literatura indígena. Caracas: Ministerio de Educación, Cultura y Deportes.

2007. Hablemos... Caracas: Planeta.

Mosonyi, Esteban Emilio y Jorge Pocaterra. 2004. Experiencias recientes de revitalización lingüística en la Venezuela Indígena. Ponencia presentada en el Foro Barcelona 2004 http://www.barcelona2004.org/esp/banco_del_conocimiento/docs/PO_35_ES_ POCATERRA.pdf. Consulta: 15 de febrero de 2010.

Pérez, Luis Adolfo. 2004. "Los wayuu: tiempos, espacios y circunstancias". Espacio abierto. 13 (4): 607-630.

Primera, Maye. 2007. "Alemania en Venezuela”. Travesías. 64. http://www.revistatravesias. $\mathrm{com} /$ numero-64/articulos-principales/alemania-en-venezuela.html. Consulta: 14 de marzo de 2010.

Serrón, Sergio. 2007a. "Bilinguismo, interculturalidad y educación, las comunidades indígenas y sorda de Venezuela, una aproximación". Opción. 53: 52-71.

2007b. "Unidad lingüística hispanoamericana: una revisión desde la óptica de la planificación lingüística y de la enseñanza de la lengua". Hispanista. 7 (18). http:// www. hispanista.com.br/revista/artigo40esp.htm. Consulta: 02 de abril de 2010.

Varela, Francisco, Humberto Maturana y Ricardo Uribe. 1974. "Autopoiesis: the organization of living systems, its characterization and a model". Biosystems. 5: 187-196.

XIII Censo General de Población y Vivienda. 2001. Venezuela: Instituto Nacional de Estadística. 